\title{
The Discrete Space Vector Modulation Strategy for the Permanent Magnet Synchronous Machine with Large Inertia
}

\author{
Chen.Wei Zhou.Xin \\ School of Electrical Engineering and Automation Tianjin University \\ Tianjin, China \\ chen wei@tju.edu.cn
}

\begin{abstract}
In order to reduce the torque ripple and improve the dynamic performance, a direct torque control strategy with special discrete space vector modulation (DSVM) for the permanent magnet synchronous motor (PMSM) control system with large inertia is proposed in this paper. With this discrete space vector modulation strategy, more voltage vectors will be generated that the electromagnetic torque variation will be controlled and the undesired torque will be restrained. An improvement of the drive performance can be obtained using the DVSM. Numerical simulations have been carried out to validate the proposed method.
\end{abstract}

Keywords-permanent magnet synchronous motor; large inertia; direct torque control; discrete space vector modulation

\section{Introduction}

The permanent magnet synchronous motor (PMSM) is widely used in the industry including the flywheel energy storage system, wind turbine system and electric propulsion system, due to its small volume, low weight, and high efficiency especially in the system with large inertia.

The direct torque control method which was proposed by Professor M. DePenbrok and I. Takahashi for induction machines in the middle of 1980's is applied to control the PMSM with large inertia. And this method has become more and more popular nowadays because of its simple structure and strong robustness indicated in [1]. Compared with other control methods, the direct torque control system can eliminate the PI regulators, ABC-dq coordinate transformation, current regulators and the PWM signal generator. It satisfies the features of the precise and quick torque control and the reduction of the complexity in the whole system in [2-4].

The predictive control and the back stepping control to eliminate the torque ripple are mentioned in [5-6]. The prediction of the flux and torque is the expected values, so the torque and flux will be satisfied with the given values in the next time. The direct torque control with the space vector modulation is presented in [7-9]. The algorithms are too complex to be practical for the high-speed machine. Hysteresis comparators can be replaced by the sliding mode control in [10-13] to elim- inate the hysteresis comparator shortcomings.

In this paper, the PMSM with large inertia is controlled by the direct torque method with the discrete space vector modulation (DSVM). The DSVM is not to change the structure of the direct torque control but to maintain the control method simple without adding the power circuit and the inverter switching frequency. The simulation results verify that PMSM with large inertia has good dynamic performance and the torque ripple of the system is restrained effectively.

\section{System Model}

A mathematical model representing the real system with sufficient accuracy is necessary. Based on the models, the behavior of variables of interest can be predicted.

The electromagnetic torque can be expressed:

$$
T_{\mathrm{e}}=\frac{3}{2} p\left[\frac{\psi_{\mathrm{f}}\left|\psi_{\mathrm{s}}\right|}{L_{\mathrm{d}}} \sin \delta_{\mathrm{sm}}+\frac{L_{\mathrm{d}}-L_{\mathrm{q}}}{2 L_{\mathrm{d}} L_{\mathrm{q}}}\left|\psi_{\mathrm{s}}\right|^{2} \sin 2 \delta_{\mathrm{sm}}\right]
$$

Because of this paper uses the surface mount permanent magnet synchronous motor as the motor/generator, $L_{\mathrm{d}}=L_{\mathrm{q}}=L_{\mathrm{s}}$ and $L_{\mathrm{s}}$ is the stator inductance. Equation (1) is rewritten as:

$$
T_{\mathrm{e}}=\frac{3}{2} p \frac{\psi_{\mathrm{f}}\left|\psi_{\mathrm{s}}\right|}{L_{\mathrm{s}}} \sin \delta_{\mathrm{sm}}
$$

The stator flux linkage of the PMSM can be calculated by (3):

$$
\psi_{\mathrm{s}}=\int\left(u_{\mathrm{s}}-i_{\mathrm{s}} R_{\mathrm{s}}\right) \mathrm{d} t
$$

Neglecting the stator's resistance, equation (4) can be changed into:

$$
\psi_{\mathrm{s}}=\int u_{\mathrm{s}} \mathrm{d} t
$$

Making the system discrete, equation (5) was written to: 


$$
\psi_{\mathrm{s}(k+1)}=\psi_{\mathrm{s}(k)}+u_{\mathrm{s}} \Delta t
$$

In equation (10), $k$ is any simple time, $k=1,2, \ldots \ldots$

\section{Control Strategy}

In this paper the number of voltage vectors is increased using a standard VSI topology and introduced a simplified space vector modulation technique-DVSM. The DVSM generates new voltage vectors and the magnitude are $1 / 3$ and $2 / 3$ original's respectively; new vectors are synthesized by the two boundary vectors as shown in Fig. 1.

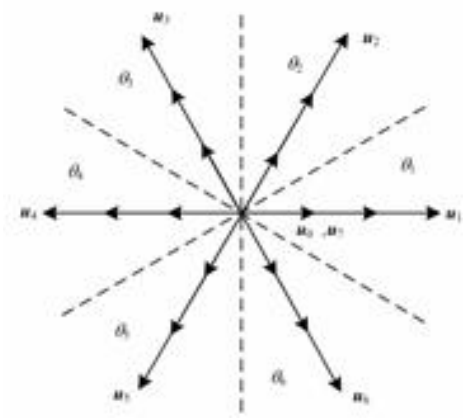

Fig. 1. Distribution of the discrete vectors and sectors

The block diagram of the direct torque control with the DSVM is shown in Fig. 2.

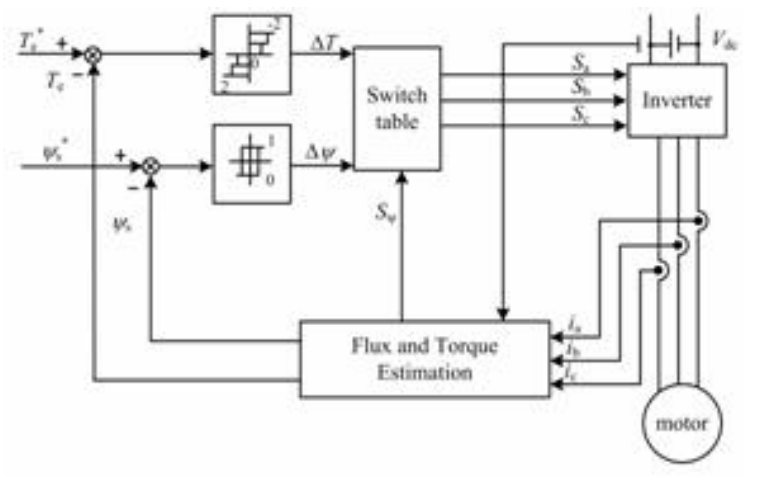

Fig. 2. The direct torque control based on DVSM

The direct torque control with the DSVM consists of the flux and torque hysteresis comparators, the flux and torque estimators, switching tables and the inverter. $S_{\psi}$ is the sector of the stator flux, the whole control system is not changed.

\section{Simulation Results}

In order to show the effectiveness of the proposed method, a numerical simulation has been carried out on the PMSM. The following table shows the parameters of the PMSM.

Table 1. Parameter of The PMSM with The Large Inertia

\begin{tabular}{|c|c|}
\hline Parameter & Values \\
\hline Rated voltage $U_{\mathrm{N}}(\mathrm{V})$ & 380 \\
\hline Rated power $P_{\mathrm{N}}(\mathrm{kW})$ & 1.5 \\
\hline Rated speed $n_{\mathrm{N}}(\mathrm{r} / \mathrm{min})$ & 1000 \\
\hline Rotational inertia $J\left(\mathrm{~kg} \cdot \mathrm{m}^{2}\right)$ & 0.5 \\
\hline Permanent magnet flux linkage $\psi_{\mathrm{r}}(\mathrm{V} \cdot \mathrm{s})$ & 0.24 \\
\hline Stator resistance $R_{\mathrm{s}}(\Omega)$ & 0.975 \\
\hline Stator inductance $L_{\mathrm{s}}(\mathrm{mH})$ & 8.5 \\
\hline
\end{tabular}

Fig. 3 (a) is the waveform of the motor velocity, the torque with the DTC and (b) is the DTC with DVSM. It can be seen from the waveform that direct torque control of the PMSM with large inertia meets its required control performance. The phase B current has a little serious distortion and owns a good sinusoidal waveform as shown in the Fig. 4 (a).
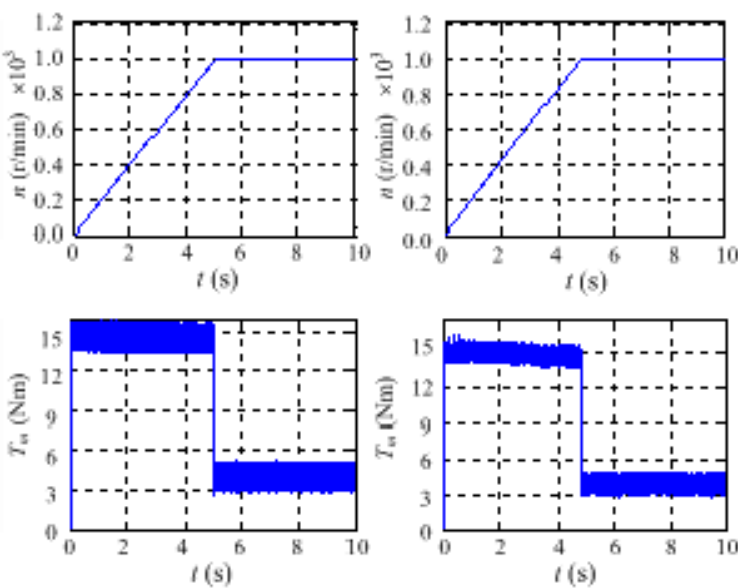

(a)

(b)

Fig. 3. Waveform of the speed and the torque from $0 \mathrm{r} / \mathrm{min}$ to $1000 \mathrm{r} / \mathrm{min}$. (a) Traditional DTC. (b) DTC with DVSM

Fig. 3 (b) shows the waveform of the system based on the direct torque control and DVSM. The discrete space voltage vector modulation method does not affect the overall system performance. The system still 
spends about $4.8 \mathrm{~s}$ to reach its steady state and the phase $B$ current maintains a better sine wave than the traditional DTC method as shown in the Fig. 4 (b). And the electromagnetic torque ripple has been suppressed.
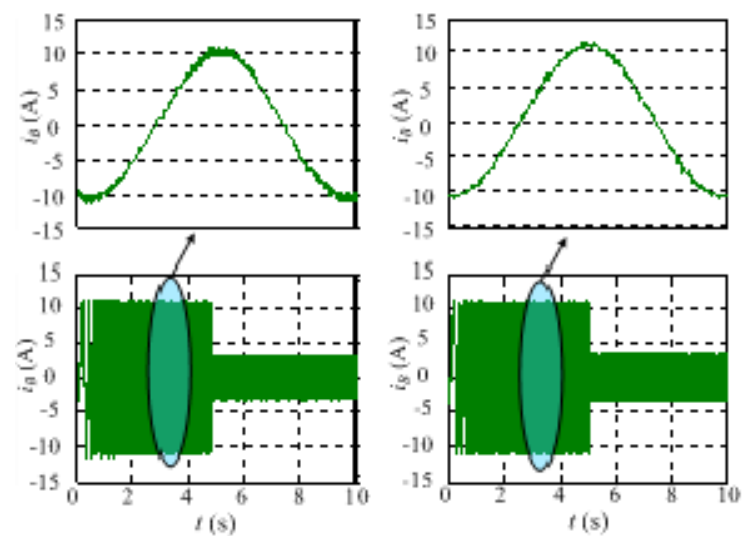

(a)

(b)

Fig.4. Waveform of phase B current and the zoom picture from 0 $\mathrm{r} / \mathrm{min}$ to $1000 \mathrm{r} / \mathrm{min}$. (a) Traditional DTC. (b) DTC with DVSM
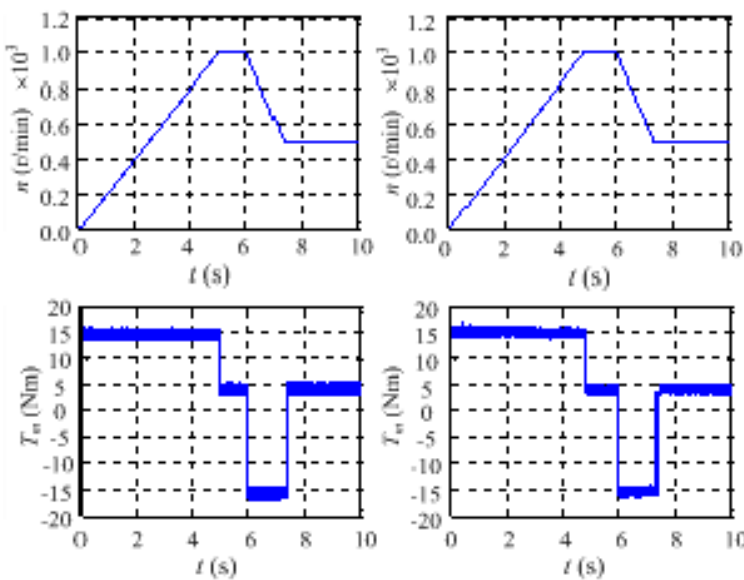

(a)

(b)

Fig.5. Waveform of the speed and the torque from $0 \mathrm{r} / \mathrm{min}$ to $1000 \mathrm{r} / \mathrm{min}$ and to $500 \mathrm{r} / \mathrm{min}$. (a) Traditional DTC. (b) DTC with DVSM

It can be seen from Fig. 5 (a), the system with the traditional direct torque control has good dynamic response, and the short transient process which meets the fast performance of the PMSM with large inertia. The electromagnetic torque waveform is good, but its large torque ripple also affects the motor stator current as show in the Fig. 5 (a) and other operating results.

But the Fig. 5 (b) shows the PMSM with large inertia based on the discrete voltage vector modulation and direct torque control is still operated in the same conditions. From the Fig. 5 (b), it can be seen that the original system's dynamic response is not affected by discrete voltage vector modulation; and the phase B current does not have the serious distortion, and the current has less harmonics compared with the traditional DTC method from the Fig. 6 (b).
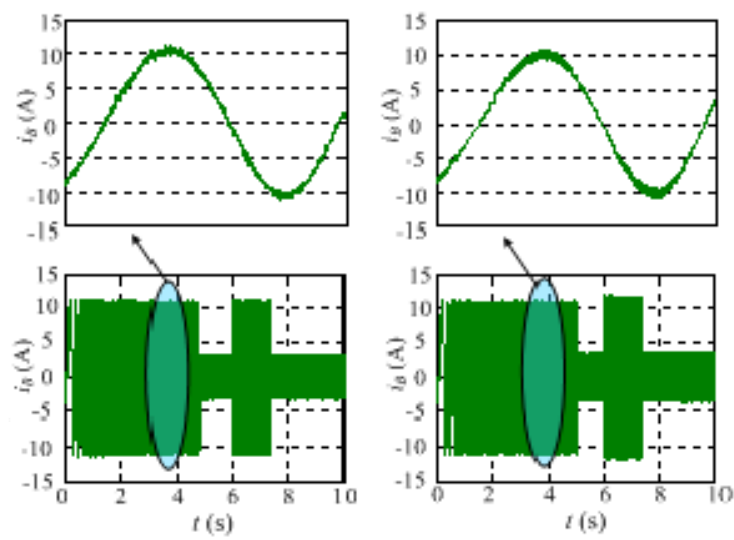

(a)

(b)

Fig. 6. Waveform of phase B current and the zoom picture from $0 \mathrm{r} / \mathrm{min}$ to $1000 \mathrm{r} / \mathrm{min}$ and to $500 \mathrm{r} / \mathrm{min}$. (a) Traditional DTC. (b) DTC with DVSM

\section{Conclusion}

In this paper, direct torque control method is used to control the PMSM with large inertia. Compared with other control methods, the system with direct torque control has better dynamic characteristics. The torque ripple which causes by direct torque control itself is restrained by using the discrete space vector modulation, and the discrete space vector modulation does not affect the direct toque control method. Matlab simulation results verify the effectiveness of this method.

\section{Reference}

1. L. Zhong, M. F. Rahman, W. Y. Hu, K. W. Lim.: Analysis of Direct Torque Control in Permanent Magnet Synchronous Motor Drives. In: IEEE Trans. Power Electronics. vol. 13, pp. 528-536, May 1997.

2. Casadei. D, Profumo. F, Tani. A, Serra. G.: FOC and DTC: Two Viable Schemes for Induction Motors Torque Control. In: IEEE Trans. Power Electronics. vol. 17, pp. 779-787, Sep. 2002.

3. M. F. Rahman, L. Zhong, Md. Enamul. Haque, M. A. Rahman.: A Direct Torque-Controlled Interior PermanentMagnet Synchronous Motor Drive Without a Speed Sensor. 
In: IEEE Trans. Energy Conversion. vol. 18, pp. 17-22, March 2003.

4. L. Zhong, M. F. Rahman, W. Y. Hu, K. W. Lim, M. A. Rahman.: A Direct Torque Controller for Permanent Magnet Synchronous Motor Drives. In: IEEE Trans. Energy Conversion. vol. 14, pp.637-642, Sep. 1999.

5. Carlos. Ortega, Antoni. Arias, Cedric. Carauna, Josep. Balcells, Greg. M. Asher.: Improved Waveform Quality in the Direct Torque Control of Matrix-Converter-Fed PMSM Drives. In: IEEE Trans. Industrial Electronics. vol. 57, pp. 2101-2110, June 2010.

6. G. Foo, M. F. Rahman.: Direct Toque and Flux Control of An IPM Synchronous Motor Drive Using a Back stepping Approach. In: IET Trans. Electric Power Applications. vol. 3, pp. 413-421, April 2009.

7. L. Tang, L. Zhong, M. F. Rahman, Y. Hu.: A novel Direct Torque Control Scheme for Interior Permanent Magnet Synchronous Machine Drive System with Low Ripple in Torque and Flux, and Fixed Switching Frequency. In: Proc. IEEE Symp. Power Electronics Specialists Conference (PESE 02), IEEE Press, Oct. 2002, pp. 529-534.

8. L. Tang, L. Zhong, M. F. Rahman, Y. Hu.: A Novel Direct Torque Controlled Interior Permanent Magnet Synchronous Machine Drive with Low Ripple in Flux and Torque and Fix Switching Frequency. In: IEEE Trans. Power Electron- ics. vol. 19, pp. 346-354, March 2004.

9. J. Zhang, Z. Xu, L. Tang, M. F. Rahman.: A Novel Direct Load Angle Control for Interior Permanent Magnet Synchronous Machine Drives with Space Vector Modulation. In: Proc. IEEE Symp. Power Electronics and Drives Systems Conference (PEDS 05), IEEE Press, April 2005, pp. 607611.

10. Cristian. Lascu, Ion. Boldea, Frede. Blaabjerg.: Direct Torque Control of Senseless Induction Motor Drives: A Sliding-Mode Approach. In: IEEE Trans. Industrial Applications, vol. 40, pp. 582-590, March-April 2004.

11. Z. Xu, M. F. Rahman. :Direct Torque and Flux Regulation of An IPM Synchronous Motor Drive Using Variable Structure Control Approach. In: IEEE Trans. Power Electronics. vol. 22, pp. 2487-2498, Nov. 2007.

12. Yasser. Abdel-Rady. Ibrahim. Mohamed.: Direct Instantaneous Torque Control in Direct Drive Permanent Magnet Synchronous Motors-A New Approach. In: IEEE Trans. Energy Conversion. vol. 22, pp. 829-838, Dec. 2007.

13. Yasser. Abdel-Rady. Ibrahim. Mohamed.: A Newly Designed Instantaneous-Torque Control of Direct-Drive PMSM Servo Actuator with Improved Torque Estimation and Control Characteristics. In: IEEE Trans. Industrial Electronics. vol. 54, pp. 2864-2873, Oct. 2007. 